\title{
LAS MIGRAÑAS DE CLARÍN
}

\author{
GONZÁLEZ-MARTÍN-MORO J ${ }^{1}$
}

Recientemente he terminado de leer La Regenta (1), la que es considerada tras el Quijote, la mejor novela de la Literatura española. Si de algo queda el lector impresionado es de la basta cultura de Clarín (son abundantísimas las citas literarias), pero además el trasfondo médico de la novela es impresionante y son continuas las referencias a la enfermedad, al médico y a la medicina (2), y no es de extrañar si tenemos en cuenta que en ese momento la medicina y la cirugía estaban sufriendo una prodigiosa transformación.

En 1846 Morton había llevado a cabo en el Hospital General de Massachussets la que se considera la primera anestesia general de la era moderna. Poco después (1858) Rudolf Virchow (al que incluso se hace en alguna ocasión referencia directa en la novela), anuncia su teoría celular. En 1859 Darwin edita El origen de las especies, y había introducido el concepto de la selección natural, concepto al cual son continuas las referencias, y en 1865 las leyes genéticas de Mendel ven la luz. Apenas una década antes de la aparición de la novela, en 1867 Lister

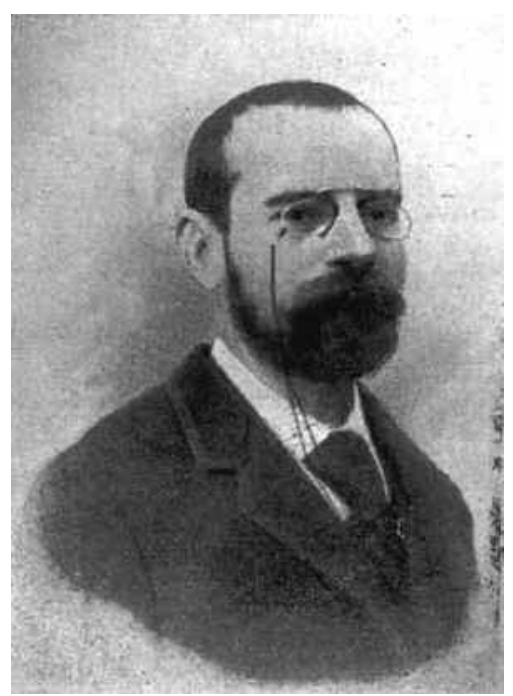

Fig. 1: Retrato del autor. había publicado su más importante obra, que daba inicio a la era de la antisepsia en la práctica de la cirugía (On the Antiseptic Principle in the Practice of Surgery). Vencidos el dolor, la hemorragia y la infección se hacía posible el inicio de la cirugía abdominal, torácica y la neurocirugía. Además la edición de la novela coincide con un tiempo en el que la microbiología está en plena expansión. Fue en el mismo año de la publicación de la Regenta (1885) cuando el catalán Ferrán, puso en práctica la que se considera la primera vacuna de la era moderna (aplicada durante el brote de cólera de 1885 en Valencia). Pocos meses después Pasteur presentaría su vacuna antirrábica.

En este retrato costumbrista, cada uno de los personajes es descrito de forma impecable, y en muchas ocasiones se describe de forma igualmente precisa la enfermedad que padecen. La novela finaliza con la muerte de Don Víctor en duelo, como

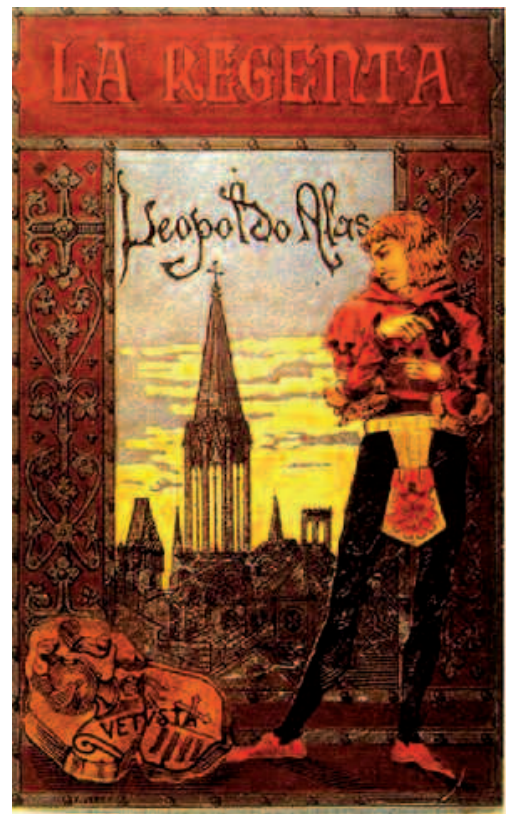

Fig. 2: Portada de la primera edición de la Regenta.

\footnotetext{
1 Licenciado en Medicina. Servicio de Oftalmología. Hospital La Princesa. Madrid. España. E-mail: juliogmm@yahoo.es
} 
consecuencia de la peritonitis desencadenada tras la perforación vesical. Clarín no escatima detalles, y el proceso es descrito con tal minuciosidad que ya ha sido objeto de alguna publicación (3).

En el capítulo primero aparece una descripción de la migraña clásica muy precisa (... Se tomó el pulso, se miró las manos; no veía bien los dedos, el pulso latía con violencia; en los párpados le estallaban estrellitas, como chispas de fuegos artificiales, sí, sí estaba mala, iba a darle el ataque... Era el ataque aunque no estaba segura de que viniese con todo el aparato nervioso de costumbre; pero los síntomas los de siempre; no veía, le estallaban chispas de brasero en los párpados y en el cerebro, se le enfriaban las manos, y de pesadas no le parecían suyas... Petra corrió a la cocina sin esperar órdenes; ya sabía lo que se necesitaba, tila y azahar... Don Victor se tranquilizó. «Estaba acostumbrado al ataque de su querida esposa; padecía la infeliz, pero no era nada.»). La descripción del proceso es impecable. Probablemente una descripción tan perfecta de los síntomas de esta enfermedad, sólo la pueda hacer alguien muy familiarizado con ella. No siendo Clarín neurólogo ni oftalmólogo, lo más probable es que el mismo sufriera migrañas, tal y como queda documentado en una carta a Galdós fechada en junio de 1884 (... cada pocos días me dan jaquecas con un acompañamiento de fenómenos nerviosos, pérdida del habla y otras menudencias que son una delicia; el primer síntoma es perder la vista...) (2). Estas crisis en muchos casos se acompañaban de disfasia. Algunos autores incluso se aventuran a afirmar que puesto que Clarín era zurdo, tendría sus centros del lenguaje alojados en el hemisferio derecho y que fuera el hemicráneo derecho lo que probablemente le doliera al ilustre escritor (2).

\section{BIBLIOGRAFÍA}

1. Leopoldo Alas «Clarín». La Regenta. Madrid: Editorial Castalia; 1981; 174-175.

2. Izquierdo Rojo JM. A remembrance of Clarín's illnesses in his centenary. An R Acad Nac Med (Madr). 2002; 119: 327-339.

3. Fariña Pérez LA. Una herida de bala vesical. En la novela «La Regenta» de Leopoldo Alas «Clarín». Actas Urol Esp 2000; 24: 775-778. 